\title{
The association between biopsychosocial factors and disability in a national health survey in South Africa
}

\author{
P. Naidoo, R. Sewpaul, A. Nyembezi, P. Reddy, K. Louw, R. Desai and D. J. Stein
}

\begin{abstract}
The association between psychosocial factors and disability is less clear. This study investigated the biological and psychosocial (employment and psychological distress) factors associated with level of disability in an adult sample in South Africa. Data were analysed from a cross-sectional survey among adults aged 18-64 $(n=4974)$. Multiple linear regression was used to investigate the associations of the selected variables with disability. The mean percentage score on the WHODAS scale of disability was $5.31 \%$ (95\% CI: $4.74-$ 5.88). Age $(p<0.001)$ and race $(p=0.0002)$ were significantly associated with disability, and history of stroke ( $\beta=7.19,95 \%$ CI: 3.19-11.20) and heart-related conditions ( $\beta=2.08$, 95\% CI: [0.23-3.93) showed positive associations. Of the psychosocial variables, psychological distress $(\beta=10.49[8.63-12.35])$ showed a strong positive association while employment $(-1.62[-2.36$ to -0.88$])$ showed a negative association with disability. The association between demographic factors, medical conditions and increased disability confirms the findings in the literature. The finding that psychological distress is associated with increased disability has not been frequently reported. This study highlights specific psychosocial targets that may be usefully addressed by health policies and interventions in order to improve disability management.
\end{abstract}

\section{Introduction}

The estimated prevalence of disability in Southern Africa is $24.5 \%$, higher than the world average of $15 \%$ (World Health Organization [WHO], 2011). The WHO (2001) defines disability as the outcome of the interaction between a person's health condition and the context in which the person lives, which occurs at the body, person and societal levels. Understanding disability within a Biopsychosocial (BPS) Model is therefore appropriate as it encapsulates the complex interaction of factors that result in varying levels of disability.

Non-communicable diseases (NCDs) which include stroke, heart disease, hypertension and diabetes are recognised as major causes of disability in low- and middle-income countries (LMICs) (Hoy et al., 2013; Nojilana et al., 2016). In South Africa (SA), a MIC, NCDs account for an estimated $16 \%$ of disability-adjusted life years (DALYs) (Norman, Matzopoulos, Groenewald, \& Bradshaw, 2007). NCDs share common risk factors, such as high blood pressure, elevated blood glucose, and abnormal blood lipids (Maimela et al., 2016). A 
leading cause of disability among adults is stroke (Gbiri, Olawale, \& Isaac, 2015) and 80\% of all stroke deaths occur in LMICs (Lekoubou, Nkoke, Dzudie, \& Kengne, 2015). In SA, 75,000 strokes occur each year with a third of these fatal within the first month (Bertram, Jaswal, Van Wyk, Levitt, \& Hofman, 2013). Type II diabetes also carries a high disease burden on SA with over 73,000 attributable DALYs (Bertram et al., 2013) Psychosocial factors, including psychological distress (PD) have also been associated with disability (Brenes et al., 2008; Merikangas et al., 2007; Okoro et al., 2009, 2011). Twelve-month prevalence of depression and anxiety disorders among SA adults was 4.9 and $8.1 \%$ respectively (Herman et al., 2009).

This study was located within the BPS Model of Health (Gallo \& Luecken, 2008; Suls \& Rothman, 2004). Based on a national adult sample, the study investigated the association of biological variables (age, sex, race, personal history of stroke and heart conditions, high blood pressure, blood glucose and cholesterol levels), psychosocial variables (employment status and psychological distress) and the outcome variable (disability).

\section{Method}

\section{Participants and procedures}

The study analysed data from the South African National Health and Nutrition Examination Survey (SANHANES), a household-based national survey (Shisana et al., 2014). Multi-stage disproportionate, stratified cluster sampling was used to select households within enumeration areas (EAs) stratified by province and locality type. All individuals within the 10,000 selected households were eligible to participate.

Data collection, in 2012, comprised interviews, physical examinations and collection of blood samples for clinical tests. The study received approval from the HSRC Research Ethics Committee (REC 6/16/11/11).

\section{Measures}

The degree of disability related difficulties in doing daily activities (outcome variable) was measured through self-report using the 12-item interviewer-administered WHO Disability Assessment Schedule (WHODAS 2.0) (WHO, 2010). WHODAS 2.0 measures health and disability at population level by assessing the level of functioning over the past month in six domains of life, namely, cognition, mobility, self-care, getting along with other people, life activities and participation in society. Respondents rate the level of difficulty they experience in doing various activities, from none to extreme or cannot do. Composite scores ranging from o to 48 are transformed into percentages (o-100\%) (WHO, 2010). The Cronbach's alpha for WHODAS per cent score, in this study, was 0.9.

The biological variables, age group, sex, race, a personal history of stroke and heart conditions, high blood pressure, blood glucose and cholesterol levels; and the psychosocial variables, psychological distress and employment, were used as the independent variables. 
Race allowed investigation of ongoing health disparities that have endured post-apartheid. Personal history of stroke and of heart disease were each based on respondents' self-report of having ever been told by a health professional that they had these conditions.

Respondents were classified as follows: (1) of having high blood pressure (HBP) if at least one of the following conditions were met: measured systolic blood pressure (SBP) $>=140 \mathrm{~mm} \mathrm{Hg}$, diastolic blood pressure (DBP) $\geq 90 \mathrm{~mm} \mathrm{Hg}$ or they reported currently taking medication for blood pressure; (2) of having high blood glucose levels if either their measured blood glucose level ( $\mathrm{HbA1C}$ ) was $\geq 6.5 \%$ or they reported currently taking medication for blood sugar; and (3) of having high cholesterol if either their serum total cholesterol exceeded $5 \mathrm{mmol} / \mathrm{L}$ or they reported having ever had their blood cholesterol checked and being told by a health professional that it was high.

PD was measured by the Kessler 10 (Kessler et al., 2002), a 10-item scale where scores exceeding 19 indicate a level of PD. The K10 has been validated for use in the SA context (Andersen et al., 2011). The Cronbach's alpha of the K10 in this study was 0.9.

\section{Data analysis}

Data were weighted to account for unequal sampling probabilities and to benchmark to 2012 mid-year population estimates. Adults aged 18-64 years who completed the questionnaire and clinical examinations were included in the analysis. Data were analysed using Stata 13.0 (Stata Corporation, College Station, USA). The mean percentage for level of disability measured by the WHODAS was presented for each category of the independent variables, with one-way ANOVA to determine significant differences between groups. A significance level of 0.05 was used. Simple and multiple linear regressions investigated the association of the independent variables with the WHODAS percentage score. Variables found to be significant in the bivariate models were used in the multiple regression, controlling for age, sex, race and employment status.

\section{Results}

Of the 4974 respondents (Table 1), 65.5\% were female, and 69.9\% were black African, $23.3 \%$ Coloured, 2.1\% White and 4.7\% Indian.

Overall $7.7 \%$ of respondents had a personal history of heart-related conditions; $2.1 \%$ ever had a stroke; 29.8\% had HBP; 6.7\% had high blood glucose levels, 25.4\% had high cholesterol and $18.4 \%$ were psychologically distressed.

The mean WHODAS per cent score was $5.31 \%$ (Table 2) and $61.1 \%$ of adults scored $0 \%$. Mean WHODAS per cent score increased with age group, varied significantly by sex and race, and was significantly higher among adults with a personal history of stroke, of heart related conditions, those with HBP, high blood glucose, high cholesterol, who were unemployed and who were psychologically distressed, than those who did not have each of these conditions or risk factors. 
When controlling for sex, age, race and employment status, HBP, high blood glucose and high cholesterol showed weak associations with WHODAS per cent score $(p>0.05)$ and were hence excluded from the multiple regression model. Multiple linear regression (Table 3) showed that White $(\beta=-2.43,95 \% \mathrm{CI}:-4.05$ to -0.82$)$ and Coloured ( $\beta=-1.44[-2.15$ to $-0.72])$ adults had significantly lower WHODAS per cent scores than African adults.

Table 1. Characteristics of the sample ${ }^{\mathrm{a}}$.

\begin{tabular}{lcc}
\hline & $\%$ & Count \\
\hline Total & 100.0 & 4974 \\
Age & & \\
$18-24$ & 22.9 & 1140 \\
$25-34$ & 21.7 & 1077 \\
$35-44$ & 19.3 & 960 \\
$45-54$ & 19.9 & 991 \\
$55-64$ & 16.2 & 806 \\
Sex & & 3260 \\
$\quad$ Female & 65.5 & 1714 \\
$\quad$ Male & 34.5 & 3463 \\
Race & & 103 \\
African & 69.9 & 1157 \\
White & 2.1 & 234 \\
$\quad$ Coloured & 23.3 & \\
$\quad$ Indian & 4.7 & 2941 \\
Employment status & & 1433 \\
$\quad$ Unemployed & 67.2 & \\
$\quad$ Employed & 32.8 & \\
\hline
\end{tabular}

'Table presents unweighted percentages and counts.

Table 2. Mean WHODAS percentage score by biological and psychosocial factors.

\begin{tabular}{|c|c|c|c|c|}
\hline & \multicolumn{3}{|c|}{ WHODAS percentage score } & \multirow[b]{2}{*}{$n$} \\
\hline & Mean $(\%)$ & SE & $p$-Value (one-way ANOVA) & \\
\hline Total & 5.31 & 0.29 & & 4974 \\
\hline \multicolumn{5}{|l|}{ Age } \\
\hline $18-24$ & 3.99 & 0.5 & \multirow[t]{5}{*}{$<0.001$} & 1140 \\
\hline $25-34$ & 3.55 & 0.35 & & 1077 \\
\hline $35-44$ & 4.91 & 0.54 & & 960 \\
\hline $45-54$ & 7.05 & 0.52 & & 991 \\
\hline $55-64$ & 9.54 & 0.74 & & 806 \\
\hline \multicolumn{5}{|l|}{ Sex } \\
\hline Female & 5.79 & 0.32 & \multirow[t]{2}{*}{0.003} & 3260 \\
\hline Male & 4.58 & 0.39 & & 1714 \\
\hline \multicolumn{5}{|l|}{ Race } \\
\hline African & 5.75 & 0.35 & \multirow[t]{4}{*}{0.0085} & 3463 \\
\hline White & 2.94 & 0.90 & & 103 \\
\hline Coloured & 3.06 & 0.33 & & 1157 \\
\hline Indian & 3.93 & 0.71 & & 234 \\
\hline \multicolumn{5}{|l|}{ Employment Status } \\
\hline Unemployed & 6.08 & 0.34 & \multirow[t]{2}{*}{$<0.001$} & 2941 \\
\hline Employed & 3.80 & 0.40 & & 1433 \\
\hline \multicolumn{5}{|c|}{ Personal history of stroke } \\
\hline No & 5.07 & 0.28 & \multirow[t]{2}{*}{$<0.001$} & 4825 \\
\hline Yes & 16.71 & 2.19 & & 123 \\
\hline \multicolumn{5}{|c|}{ Personal history of heart conditions } \\
\hline No & 4.78 & 0.27 & \multirow[t]{2}{*}{$<0.001$} & 4505 \\
\hline Yes & 11.05 & 0.99 & & 378 \\
\hline \multicolumn{5}{|l|}{ High blood pressure } \\
\hline No & 4.83 & 0.35 & \multirow[t]{2}{*}{0.001} & 3062 \\
\hline Yes & 6.48 & 0.43 & & 1567 \\
\hline \multicolumn{5}{|l|}{ High blood glucose } \\
\hline No & 5.12 & 0.30 & \multirow[t]{2}{*}{$<0.001$} & 4540 \\
\hline Yes & 7.90 & 0.74 & & 434 \\
\hline \multicolumn{5}{|l|}{ High cholesterol } \\
\hline No & 4.55 & 0.30 & \multirow[t]{2}{*}{0.006} & 2720 \\
\hline Yes & 6.15 & 0.54 & & 1056 \\
\hline \multicolumn{5}{|l|}{ Psychological distress } \\
\hline Low/no distress & 3.16 & 0.20 & \multirow[t]{2}{*}{$<0.001$} & 4038 \\
\hline Distressed & 14.83 & 0.93 & & 936 \\
\hline
\end{tabular}


Table 3. Association of biological and psychosocial factors with WHODAS percentage score.

\begin{tabular}{|c|c|c|c|c|c|c|}
\hline & \multicolumn{3}{|c|}{ Bivariate linear regression } & \multicolumn{3}{|c|}{ Multiple linear regression } \\
\hline & Coeff. & 95\% Cl (Coeff.) & $p$-Value & Coeff. & 95\% Cl (Coeff.) & $p$-Value \\
\hline \multicolumn{7}{|l|}{ Sex } \\
\hline Female & Ref & - & - & Ref & - & - \\
\hline Male & $-1.21^{*}$ & [ -2.01 to -0.41$]$ & 0.003 & -0.22 & {$[-1.02$ to 0.57$]$} & 0.577 \\
\hline \multicolumn{7}{|l|}{ Race } \\
\hline African & Ref & - & - & Ref & - & - \\
\hline White & $-2.81^{*}$ & [ -4.70 to -0.91$]$ & 0.004 & $-2.43^{*}$ & $\begin{array}{r}{[-4.05 \text { to }} \\
-0.82]\end{array}$ & 0.003 \\
\hline Mixed ancestry & $-2.68^{*}$ & [ -3.60 to -1.76$]$ & $<0.001$ & $-1.44^{*}$ & $\begin{array}{r}{[-2.15 \text { to }} \\
-0.72]\end{array}$ & $<0.001$ \\
\hline Indian & $-1.82^{*}$ & {$[-3.35$ to -0.28$]$} & 0.020 & -0.78 & [ -2.19 to 0.62$]$ & 0.274 \\
\hline \multicolumn{7}{|l|}{ Age group } \\
\hline $18-24$ & Ref & - & - & Ref & - & - \\
\hline $25-34$ & -0.44 & [ -1.53 to 0.64$]$ & 0.424 & -0.14 & [ -1.24 to 0.97$]$ & 0.809 \\
\hline $35-44$ & 0.92 & {$[-0.33$ to 2.17$]$} & 0.150 & 0.6 & {$[-0.72$ to 1.93$]$} & 0.371 \\
\hline $45-54$ & $3.06^{*}$ & [1.73 to 4.39$]$ & $<0.001$ & $2.61^{*}$ & [1.31 to 3.9 ] & $<0.001$ \\
\hline $55-64$ & $5.55^{*}$ & [3.90 to 7.20$]$ & $<0.001$ & $4.39^{*}$ & [2.83 to 5.96$]$ & $<0.001$ \\
\hline Employment & $-2.29^{*}$ & [ -3.15 to -1.42$]$ & $<0.001$ & $-1.62^{*}$ & $\begin{array}{r}{[-2.36 \text { to }} \\
-0.88]\end{array}$ & $<0.001$ \\
\hline Ever had a stroke & $9.70^{*}$ & [5.44 to 13.96$]$ & $<0.001$ & $7.19^{*}$ & [3.19 to 11.2$]$ & $<0.001$ \\
\hline $\begin{array}{l}\text { Personal history of } \\
\text { heart disease/ } \\
\text { heart related } \\
\text { conditions }^{\mathrm{a}}\end{array}$ & $4.76^{*}$ & [2.99 to 6.52$]$ & $<0.001$ & $2.08^{*}$ & [0.23 to 3.93 ] & 0.028 \\
\hline $\begin{array}{l}\text { Raised blood pres- } \\
\text { sure }^{\mathrm{a}}\end{array}$ & 0.27 & [ -0.79 to 1.33$]$ & 0.62 & & & \\
\hline High blood sugar ${ }^{a}$ & 1.16 & [ -0.44 to 2.76$]$ & 0.153 & & & \\
\hline High cholesterol $^{\mathrm{a}}$ & 1.14 & [ -0.07 to 2.36$]$ & 0.066 & & & \\
\hline $\begin{array}{l}\text { Psychological } \\
\text { distress }^{\mathrm{a}}\end{array}$ & $11.02^{*}$ & [9.17 to 12.86 ] & $<0.001$ & $10.49^{*}$ & [ 8.63 to 12.35 ] & $<0.001$ \\
\hline
\end{tabular}

Adults aged $45-54(\beta=2.61[1.31-3.90])$ and 55-64 $(\beta=4.39[2.83-5.96])$ had significantly higher WHODAS per cent scores than 18-24 year olds. The biological factors, personal history of stroke $(\beta=7.19[3.19-11.20])$ and of heart related conditions $(\beta=2.08$ [0.23-3.93]) were positively associated with WHODAS per cent score. In terms of the psychosocial factors, being employed was negatively associated with WHODAS score $(\beta=$ $-1.62[-2.36$ to -0.88$])$, while PD $(\beta=10.49$ [8.63-12.35]) showed a strong positive association with WHODAS per cent score.

\section{Discussion}

The results of this study re-affirm the importance of specific biological factors (stroke, heart disease, hypertension and diabetes) and psychosocial factors (psychological distress and unemployment) in predicting disability, which was relatively low in this study (Bertram et al., 2013; Kemp, Quintana, Felmingham, Matthews, \& Jelinek, 2012; Nojilana et al., 2016; Norman et al., 2007) comparative to what has been previously reported. Employed participants were shown to have lower disability scores implying that they had better cognitive, physical mobility, self-care and interpersonal relationships. A study by Jelsma and Ferguson (2004) demonstrated similar findings. The fact that black African adults were disproportionately affected by disability relative to whites and Coloureds is supported by the fact that the former faced more socio-economic disadvantage during apartheid with these disenfranchisement effects persisting, often leading to poor health outcomes (Coovadia, Jewkes, Barron, Sanders, \& McIntyre, 2009; Seekings \& Nattrass, 2002). Increasing disability with increasing age was unsurprising, given that the ageing process decreases 
optimal day-to-day functioning and increases vulnerability to onset of NCDs, especially CVD, (Mayosi et al., 2009; Medhi, Hazarika, Borah, \& Mahanta, 2006), which hinders functional capacity (Sander \& Sander, 2014).

PD, a significant predictor of disability in this study, is often understudied. PD was found in almost one in five adults, with higher prevalence among women and black African participants. Previous studies demonstrated that SA females and black Africans are disproportionately affected by mental health conditions, including depression and anxiety (Kathree, Selohilwe, Bhana, \& Petersen, 2014; Myer, Stein, Grimsrud, Seedat, \& Williams, 2008). PD is not uncommon among individuals with an existing or life-long medical condition (Kagee, 2010; Peltzer, Pengpid, \& Skaal, 2012) where these individuals report declines in their daily functioning ability (Brenes et al., 2008; Merikangas et al., 2007). Individuals with a current or chronic medical condition, who are female and/or black African are especially vulnerable to some degree of disability.

Not with-standing the fact that the main limitation of this study is self-report bias on selected measures and is cross-sectional preventing causal inferences, the study's primary contribution is the finding which highlights the importance of mental health factors such as the presence of psychological distress in predicting disability. Continued attention also needs to be paid to the biological characteristics of the sample such as HBP and increased cholesterol and blood glucose levels which places individuals at risk for CVD onset and in turn may lead to varying degrees of disability.

\section{Conclusion}

Health policy decision makers should take cognisance of the complex interaction of existing medical conditions such as heart disease or stroke, the psychosocial determinants of health and decreased functional capacity. Further in-depth investigation into how bio-psychosocial risk factors mitigate disability is required.

\section{Acknowledgments}

The Department of Health in South Africa and DFID (Department for International Development, UK) funded the SANHANES. There are no sources of conflict.

\section{Disclosure statement}

No potential conflict of interest was reported by the authors. 


\section{References}

Andersen, L., Grimsrud, A., Myer, L., Williams, D., Stein, D., \& Seedat, S. (2011). The psychometric properties of the K10 and K6 scales in screening for mood and anxiety disorders in the South African Stress and Health study. International Journal of Methods in Psychiatric Research, 20(4), 215-223.

Bertram, M. Y., Jaswal, A. V., Van Wyk, V. P., Levitt, N. S., \& Hofman, K. J. (2013). The non-fatal disease burden caused by type 2 diabetes in South Africa, 2009. Global Health Action, 6(Suppl 1), 206-212.

Brenes, G. A., Knudson, M., McCall, W. V., Williamson, J. D., Miller, M. E., \& Stanley, M. A. (2008). Age and racial differences in the presentation and treatment of generalized anxiety disorder in primary care. Journal of Anxiety Disorders, 22(7), 1128-1136.

Coovadia, H., Jewkes, R., Barron, P., Sanders, D., \& McIntyre, D. (2009). The health and health system of South Africa: Historical roots of current public health challenges. The Lancet, 374(9692), 817-834.

Gallo, L. C., \& Luecken, L. J. (2008). Physiological research methods in health psychology: Applications of the biopsychosocial model. In L. J. Luecken, L. C. Gallo, L. J. Luecken, \& L. C. Gallo (Eds.), Handbook of physiological research methods in health psychology (pp. 3-10). Thousand Oaks, CA: Sage Publications.

Gbiri, C. A., Olawale, O. A., \& Isaac, S. O. (2015). Stroke management: Informal caregivers' burdens and strians of caring for stroke survivors. Annals of Physical and Rehabilitation Medicine, 58(2), 98-103.

Herman, A. A., Stein, D. J., Seedat, S., Heeringa, S. G., Moomal, H., \& Williams, D. R. (2009). The South African Stress and Health (SASH) study: 12-Month and lifetime prevalence of common mental disorders. SAMJ. South African Medical Journal, 99(5), 339-344.

Hoy D., Rao C., Nhung N. T., Marks G., \& Hoa N. P. (2013). Risk factors for chronic disease in Viet Nam: A review of the literature. Preventing Chronic Disease, 10, 120067. Doi:10.5888/pcd10.120067

Jelsma, J., \& Ferguson, G. (2004). The determinants of self-reported health-related quality of life in a culturally and socially diverse South African community. Bulletin of the World Health Organization, 82(3), 206-212.

Kagee, A. (2010). Psychological distress among persons living with HIV, hypertension, and diabetes. AIDS Care, 22(12), 1517-1521.

Kathree, T., Selohilwe, O. M., Bhana, A., \& Petersen, I. (2014). Perceptions of postnatal depression and health care needs in a South African sample: The 'mental' in maternal health care. BMC Women's Health, 14(1), 23.

Kemp, A. H., Quintana, D. S., Felmingham, K. L., Matthews, S., \& Jelinek, H. F. (2012). Depression, comorbid anxiety disorders, and heart rate variability in physically healthy, unmedicated patients: Implications for cardiovascular risk. PLoS ONE, 7(2), e30777.

Kessler, R. C., Andrews, G., Colpe, L. J., Hiripi, E., Mroczek, D. K., Normand, S.-L., ... Zaslavsky, A. M. (2002). Short screening scales to monitor population prevalences and trends in non-specific psychological distress. Psychological Medicine, 32(6), 959-976. 
Lekoubou, A., Nkoke, C., Dzudie, A., \& Kengne, A. P. (2015). Stroke admission and casefatality in an urban medical unit in sub-Saharan Africa: A fourteen year trend study from 1999 to 2012. Journal of the Neurological Sciences, 35O(1-2), 24-32.

Maimela, E., Alberts, M., Modjadji, S. E., Choma, S. S., Dikotope, S. A., Ntuli, T. S., \& Van Geertruyden, J.-P. (2016). The prevalence and determinants of chronic noncommunicable disease risk factors amongst adults in the Dikgale Health Demographic and Surveillance System (HDSS) site, Limpopo Province of South Africa. PLOS ONE, 11(2), e0147926.

Mayosi, B. M., Flisher, A. J., Lalloo, U. G., Sitas, F., Tollman, S. M., \& Bradshaw, D. (2009). The burden of non-communicable diseases in South Africa. The Lancet, 374(9693), 934947.

Medhi, G., Hazarika, N., Borah, P., \& Mahanta, J. (2006). Health problems and disability of elderly individuals in two population groups from same geographical location. JAPI, $54,539-544$.

Merikangas, K. R., Ames, M., Cui, L., Stang, P. E., Ustun, T. B., Von Korff, M., \& Kessler, R. C. (2007). The impact of comorbidity of mental and physical conditions on role disability in the US adult household population. Archives of General Psychiatry, 64(10), 11801188.

Myer, L., Stein, D. J., Grimsrud, A., Seedat, S., \& Williams, D. R. (2008). Social determinants of psychological distress in a nationally-representative sample of South African adults. Social Science \& Medicine, 66(8), 1828-1840.

Nojilana, B., Bradshaw, D., Pillay-van Wyk, V., Msemburi, W., Laubscher, R., Somdyala, N. I., ... Dorrington, R. E. (2016). Emerging trends in non-communicable disease mortality in South Africa, 1997-2010. South African Medical Journal , 106(5), 477-484.

Norman, R., Matzopoulos, R., Groenewald, P., \& Bradshaw, D. (2007). The high burden of injuries in South Africa. Bulletin of the World Health Organization, 85(9), 695-702.

Okoro, C. A., McKnight-Eily, L. R., Strine, T. W., Crews, J. E., Holt, J. B., \& Balluz, L. S. (2011). State and local area estimates of depression and anxiety among adults with disabilities in 2006. Disability and Health Journal, 4(2), 78-90.

Okoro, C. A., Strine, T. W., Balluz, L. S., Crews, J. E., Dhingra, S., Berry, J. T., \& Mokdad, A. H. (2009). Serious psychological distress among adults with and without disabilities. International Journal of Public Health, 54(1), 52-60.

Peltzer, K., Pengpid, S., \& Skaal, L. (2012). Prevalence of psychological distress and associated factors in urban hospital outpatients in South Africa. South African Journal of Psychiatry, 18(1), 10-15.

Sander, K., \& Sander, D. (2014). Depression and psychological distress as risk factors for stroke and worse stroke recovery: Clinical implications and therapeutic options. EMJ Neurol, 1, 53-58.

Seekings, J., \& Nattrass, N. (2002). Class, distribution and redistribution in post-apartheid South Africa. Transformation: Critical Perspectives on Southern Africa, 5O(1), 1-30.

Shisana, O. L. D., Rehle, T., Simbayi, L., Zuma, K., Dhansay, A., Reddy, P., ... the SANHANES-1 Team. (2014). South African National Health and Nutrition Examination Survey (SANHANES-1) (2014th ed.). Cape Town: HSRC Press. 
Suls, J., \& Rothman, A. (2004). Evolution of the biopsychosocial model: Prospects and challenges for health psychology. Health Psychology, 23(2), 119.

World Health Organization. (2001). The World Health Report 2001: Mental health: New understanding, new hope. Geneva: Author.

World Health Organization. (2010). Measuring health and disability: Manual for WHO disability assessment schedule (WHODAS 2.O). (T. B. Üstün, N. Kostanjsek, S. Chatterji, \& J. Rehm, Eds.). Geneva: Author.

World Health Organization. (2011). World report on disability. Retrieved from http://www.who.int/disabilities/world_report/2011/report.pdf 